\title{
Mobile caecum and ascending colon syndrome in a Nigerian adult
}

\author{
J. G. Makama, A. Ahmed, Y. Ukwenya, I. Mohammed \\ Division of General Surgery, Department of Surgery, A B U Teaching Hospital, Shika-Zaria, Nigeria
}

Page | 133

Correspondenceto: DrJ G M akama, Division of General Surgery, Department of Surgery, A B U Teaching Hospital, Shika-Zaria, Nigeria. E-mail: jerlizabeth@yahoo.com

\begin{abstract}
A mobile caecum and ascending colon is a rare congenital abnormality. Its presentation as a cause of right lower abdominal pain in an adult is usually mis-diagnosed as acute appendicitis. A 42-year-old civil servant presented with a 2-year history of recurrent right lower quadrant pain of the abdomen. The pain was sharp in nature and persistent in the last 2 weeks and centered mainly in the right side of the abdomen. No other associated symptoms were noted. Laboratory investigations did not reveal obvious abnormality. A diagnosis of acute on chronic lower quadrant pain of unknown etiology was made. The patient was resuscitated and had exploratory laparatomy. No abnormalities were found other than the caecum and the whole ascending colon, which were unattached to the posterior peritoneum. Appendectomy and caecopexy, using a lateral peritoneal flap were performed. The diagnosis of mobile caecal syndrome should be considered in patients with chronic right lower quadrant pain, and appendectomy and caecopexy offers a great relief.
\end{abstract}

Keywords: Adult, ascending colon, mobile caecum, Nigerian

\section{Résumé}

UN caecum mobile et côlon ascendant est une anomalie congénitale rare. Ses présentation comme une cause de douleur abdominale inférieure droite dans un adulte est habituellement mis-Diagnosed comme appendicite aiguë. Un fonctionnaire âgé de 42 an, qui a présenté une histoire de deux ans de douleur récidivante de quadrant inférieur droit de l'abdomen.La douleur a été forte dans la nature et persistante au cours des deux-semaines et centrés principalement dans la partie droite de l'abdomen. Aucun autres symptômes associés ont été a fait remarquer. Enquêtes de laboratoire n'a révélé anomalie évidente. UN diagnostic des aigus sur la douleur chronique de quadrant inférieure d'étiologie inconnue a été établi. Patient a été resuscitated et avait laparatomy exploratoire. Aucune anomalie ne étaient autre que le caecum et le côlon ascendant ensemble, qui ont été trouvés seules pour le péritoine postérieur. Appendectomy et caecopexy, utilisant un volets péritonéale latérale ont été effectuées. Le diagnostic de syndrome de caecal mobile devrait être considérée de patients souffrant de douleur chronique de quadrant inférieure droit et appendectomy et caecopexy offre un grand soulagement.

Mots cles:-caecum mobile, côlon ascendant, du Nigeria, adult

DOI: $10.4103 / 1596-3519.56243$

PMID: 19805946

\section{Introduction}

Embyologically, the caecum and ascending colon are usually plastered retroperitneally by the posterior peritoneum. Occasionally, this normal process may be altered. ${ }^{[1]}$ Thus, the caecum and ascending colon may be suspended on a mesentery that allows the colon to rotate freely. It is a rare congenital abnormality that presents commonly during childhood with features of intestinal obstruction. ${ }^{[1,2]}$ Its presentation in adulthood is relatively rare. ${ }^{[2,3]}$ We report a case in a Nigerian adult. 


\section{Case Report}

A 42-year-old civil servant presented with a 2-year history of recurrent right lower quadrant pain of the abdomen. The pain was sharp in nature and persistent in the last 2 weeks and centered mainly in the right side of the abdomen. No other associated symptoms were noted. He had extensive evaluation and work up previously in a peripheral hospital, but no etiology for his pain was found.

Physical examination revealed a middle-aged man, who was well nourished and not pale. He was afebrile with a temperature of $37.2^{\circ} \mathrm{C}$. The cardiopulmonary status was normal with a pulse rate of 82 , blood pressure of 120/76 $\mathrm{mmHg}$ and lung fields were clear.

The abdomen was flat, soft with marked tenderness in the right lower quadrant. However, there was no mass and Alvarado's score for appendicitis was 2 which were very low. Digital rectal examination was normal.

Haemogram was within normal. Abdomino-pelvic ultrasound was normal too. Barium study with manipulation to determine a change in position of the caecum and ascending colon radiologically would have helped, if preoperative diagnosis was entertained. However, this was not possible in this patient due to preoperative diagnostic dilemma. Thus, barium study done without manipulation was within normal limits. After resuscitation, he consented to exploratory laparatomy for an acute on chronic abdominal pain of unknown etiology. No abnormalities were found other than the caecum and the whole ascending colon, which were unattached to the posterior peritoneum, have entirely a well form mesentery.

Appendectomy and caecocolopexy, using a lateral peritoneal flap were performed. The histology of the appendix was normal. He was pain-free in the postoperative period and has remained so in the last 1 year.

\section{Discussion}

Abnormal mobility of the caecum and ascending colon has been estimated to occur in $10-20 \%$ of population. ${ }^{[3,4]}$ Despite the high incidence of anatomic variant, abnormal caecal mobility and ascending colon is an uncommon cause of an acute clinical entity. ${ }^{[3-5]}$

Embryologically, this abnormality is the result of failure of the right colonic mesentery to fuse with the lateral peritoneum. As a result, the caecum and ascending colon are unattached and are free to rotate. Despite this, they usually reside in a normal anatomic position. ${ }^{[5]}$ This, probably, may explain the reason why the abdominal ultrasound and barium studies appeared normal in this patient.

Common symptoms include colicky pain and abdominal distention, usually relieved by passing flatus, stool, or with an enema. ${ }^{[3-6]}$ In this patient, the only symptom he presented with was recurrent right lower quadrant abdominal pain which became severe and unbearable in the last 2 weeks. Mobile caecum and ascending colon and fixation at a point (a fulcrum about which torsion may occur) are said to be major pre-requisites for caecal volvulus in patient with this problem. However, our patient did not develop caecal volvulus at any point in the course of his illness, probably because there was no fulcrum. The whole ascending colon up to the transverse colon had a mesentery [Figure 1].

Caecopexy, using lateral peritoneal flap, which was first described by Dixon and Meyers in $1948^{[7,8]}$ is said to be the surgical technique of choice. This technique has stood the test of time and best achieves fixation of the caecum. In this case, the caecum and ascending colon were involved, thus "lateral caecocolopexy" was done. However, in the recent time, the laparoscopic approach is gaining much popularity. ${ }^{[9,10]}$ Other techniques, which include simply suturing the caecum and ascending colon to the lateral peritoneum and interposition with a sponge, have a high rate of recurrence. ${ }^{[11]}$

First, the peritoneum lateral to the unattached portion of the colon is incised. A flap of peritoneum is then carefully raised, with care being taken not to injure any retroperitoneal structure. The caecum and ascending colon are placed under the peritoneal flap and the free edge at the flap is sutured to the taenia coli using interrupted non-absorbable sutures, Dixon and Meyers. ${ }^{[7]}$ The colon is thereby

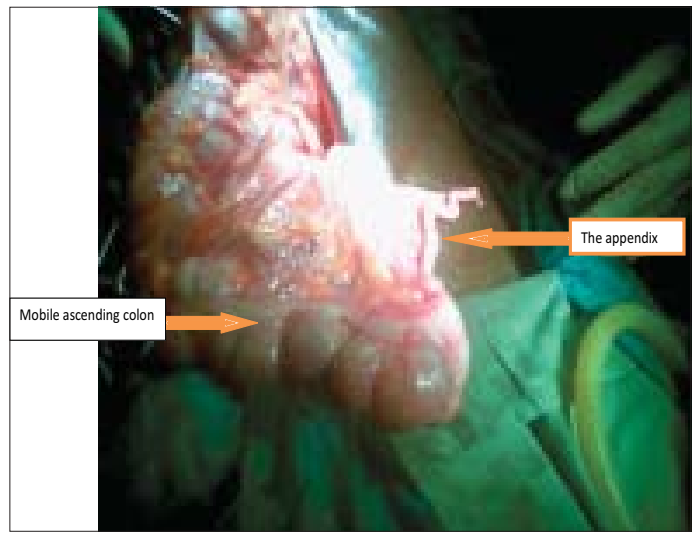

Figure 1: The caecum and ascending colon have a mesentery 
fixed partially to the retroperitoneum. ${ }^{[3,11]}$

\section{Conclusion}

The diagnosis of mobile caecal syndrome should be considered in patients with chronic right lower quadrant pain. Caecocolopexy, using the lateral peritoneal flap, is an effective method of fixing the caecum and ascending colon and prevents subsequent caecal volvulus. ${ }^{[3,9,10]}$

\section{References}

1. Husain K, Fitzgerald P, Lau G. Caecovolvulus in the Cornelia de Lange syndrome. J Paediatr Surg 1994;29:1245-7.

2. Printen KJ. Mobile caecal syndrome in the adult. Am Surg 1976;42:204-5.

3. Rogers RL, Harford FJ. Mobile caecum syndrome. Dis Colon Rectum 1984;27:399-402.

4. Lee YJ, Lee YA, Liu TJ, Chang TH. Mobile caecum syndrome: A report of two cases. Zhonghua Yi Xue Za
Zhi (Taipei) 1996;57:380-3.

5. Pirro N Corroller LE, Solari C, Merad A, Sielezneff I, Sastre B, Champsaur P, etal. Caecal volvulus: Anatomical bases and physiopathology. Morphologie 2006;90:197-202.

6. Haskin PH, Teplick SK, Teplick JG Haskin ME. Volvulus of the caecum and the right colon. JAM A 1981;245:2433-5.

7. Dixon CF, Meyer AC. Volvulus of the caecum. Surg Clin North Am 1948;28:953-63.

8. Ris HB, Stirnemann H, Doram JE. The mobile caecum syndrome appendectomy and caecopexy or only appendectomy? Chirurg 1989;60:277-82.

9. Tsushimi T, Kurazumi H, Takemoto Y, Oka K, Inokuchi T, Seyama A, et al. Laparoscopic caecopexy for mobile caecum syndrome manifesting as caecal volvulus: Report of a case. Surg Today 2008;38:359-62.

10. Thanapongsathron W, Kanjanabut B, Vaniyapong $\mathrm{T}$, Thaworncharoen S. Chronic right lower quadrant abdominal pain: Laparascopic approach. J Med Assoc Thai 2005;88:542-7.

11. El-Katib U. Volvulus of the caecum: Caecopexy by polyvinyl alcohol sponge. BrJ Surg 1973;60:475-8.

Source of Support: Nil, Conflict of Interest: None declared. 